\title{
Dehydrostephanine Isolated from Stephania venosa Possesses Anti-Inflammatory Activity in Lipopolysaccharide-Activated RAW264.7 Macrophages
}

\author{
Wanatsanan CHULRIK ${ }^{1}$, Chutima JANSAKUN ${ }^{1}$, \\ Waraluck CHAICHOMPOO ${ }^{2}$, Janejira HATA ${ }^{2}$, Poonsit HIRANSAI ${ }^{1}$, \\ Wilanee CHUNGLOK ${ }^{3}$, Tanyarath UTAIPAN ${ }^{4}$, \\ Apichart SUKSAMRARN ${ }^{2}$ and Warangkana CHUNGLOK ${ }^{1, *}$
}

\author{
${ }^{1}$ School of Allied Health Sciences and Research Institute for Health Sciences, Walailak University, \\ Nakhon Si Thammarat 80161, Thailand \\ ${ }^{2}$ Department of Chemistry and Center of Excellence for Innovation in Chemistry, Faculty of Science, \\ Ramkhamhaeng University, Bangkok 10240, Thailand \\ ${ }^{3}$ Department of Microbiology, Faculty of Science, Prince of Songkla University, \\ Songkhla 90110, Thailand \\ ${ }^{4}$ Department of Pre-clinic, Faculty of Science and Technology, Prince of Songkla University, \\ Pattani Campus, Pattani 94001, Thailand
}

('Corresponding author's e-mail: cwarang@wu.ac.th)

Received: 7 March 2019, Revised: 19 June 2019, Accepted: 9 July 2019

\begin{abstract}
Stephania venosa (Blume) Spreng. is a medicinal herb wildly used as a folklore medicine in Thailand. Many studies have reported that $S$. venosa tuber revealed a variety of pharmacological activities including anti-malarial, anti-microbial, anti-cancer, anti-oxidant, and anti-inflammatory activities. In this study, we investigated the effects of (-)-stephanine and dehydrostephanine isolated from $S$. venosa tuber on anti-inflammation in lipopolysaccharide (LPS)-activated RAW264.7 macrophages. RAW264.7 cells were treated with $(-)$-stephanine and dehydrostephanine in the presence of LPS and cell viability was determined by MTT assay. The levels of inflammatory mediators, nitric oxide (NO) and pro-inflammatory cytokines were determined by Griess reagent and enzyme-linked immunosorbent assay, respectively. Pre-treatment of dehydrostephanine significantly suppressed NO secretion in LPS-activated RAW264.7 cells with the half-maximal NO inhibitory concentration $\left(\mathrm{IC}_{50}\right)$ value of $26.81 \pm 0.25 \mu \mathrm{M}$. However, (-)-stephanine had $\mathrm{IC}_{50}$ value on the inhibition of $\mathrm{NO}$ secretion of $>40 \mu \mathrm{M}$. In addition, dehydrostephanine at concentrations of $20-80 \mu \mathrm{M}$ significantly reduced LPS-induced tumor necrosis factor- $\alpha$, interleukin-1 $\beta$, and interleukin- 6 production in RAW264.7 cells. The present study showed that dehydrostephanine possesses the anti-inflammatory effect on LPS-activated RAW264.7 macrophages by suppression of inflammatory mediators. Dehydrostephanine may be a promising candidate compound for further investigation of a novel class of anti-inflammatory drug.
\end{abstract}

Keywords: Stephania venosa, (-)-stephanine, dehydrostephanine, aporphine alkaloids, inflammation 
http://wjst.wu.ac.th

\section{Introduction}

Chronic inflammatory condition can cause several diseases such as rheumatoid arthritis, inflammatory bowel disease, type 2 diabetes mellitus, cardiovascular, and neurodegenerative disorders as well as various types of cancers [1,2]. The first line of host defense against pathogens is the innate immune system that is mediated by phagocytes especially macrophages [3]. When macrophages are exposed to inflammatory stimuli such as lipopolysaccharide (LPS), an endotoxin of Gram-negative bacteria, LPS binds to the Toll-like receptor 4 (TLR4) on the cell membrane and subsequently induces a large number of inflammatory mediators, including cytokines, chemokines, prostaglandin $\mathrm{E}_{2}\left(\mathrm{PGE}_{2}\right)$, superoxide radicals, and nitric oxide (NO) [4]. These mediators serve to trigger or enhance specific aspects of the inflammatory response. The overproduction of pro-inflammatory mediators that produce from macrophage including tumor necrosis factor- $\alpha$ (TNF- $\alpha$ ), interleukin (IL)-6, IL-1 $\beta$, inducible nitric oxide synthase (iNOS)/NO, and cyclooxygenase (COX-2)/ $\mathrm{PGE}_{2}$ would lead to poor prognosis of the diseases [5]. Potent anti-inflammatory agents that attenuate the activities of inflammatory macrophages can be used for treating chronic inflammatory diseases [6].

Stephania venosa (Blume) Spreng., a species of plant belonging to Menispermaceae family, is the prominent folklore herb of interest and is one of the most popular medicinal plants used for the treatment of various diseases [7-10]. The plants of the genus Stephania have been used as a folk remedy for multiple purposes such as diabetes mellitus, nerve tonic, appetizer, asthma, and cancer [11]. (-)-Stephanine and dehydrostephanine are aporphine alkaloids isolated from $S$. venosa $[8,10,12]$. The reported data showed that aporphine alkaloids are major compounds found in this plant and the main phytochemical constituents of this genus [11]. Aporphine alkaloids possess a tetracyclic framework which is composed of a tetrahydroisoquinoline substructure and belongs to the isoquinoline class of alkaloids [10]. Many studies have reported that alkaloids from the tuber of $S$. venosa can reveal a variety of pharmacological activities including anti-proliferative [10,13], anti-invasive [14], anti-HIV-1 integrase [15], and anti-acetylcholinesterase activities [7]. Furthermore, aporphine alkaloids $O$-methylbulbocapnine and dicentrine from the tuber of $S$. venosa can inhibit the expression of iNOS and COX-2 as well as TNF$\alpha$ and IL-6 production in LPS-activated RAW264.7 cells via the suppression of mitogen-activated protein kinases (MAPKs), phosphatidylinositol 3-kinase/Akt (PI3K/Akt), activator protein-1 (AP-1), and nuclear factor kappa B (NF-kB) activation [9]. However, there are no reports with regards to the antiinflammatory activity of (-)-stephanine and dehydrostephanine isolated from $S$. venosa. We, therefore, investigate the anti-inflammatory effects of these 2 isolated alkaloids in LPS-activated RAW264.7 macrophages.

\section{Materials and methods}

\section{Chemicals and reagents}

LPS from Escherichia coli 0111:B4, 3-(4,5-dimethylthiazol-2-yl)-2,5-diphenyltetrazolium bromide (MTT), dimethyl sulfoxide (DMSO), dexamethasone, sulfanilamide, and naphthylethylene were purchased from Sigma-Aldrich Corp. (St. Louis, MO, USA). Enzyme-linked immunosorbent assay (ELISA) kits were obtained from BioLegend (San Diego, CA, USA).

\section{Plant materials}

The tubers of $S$. venosa were collected from Prachin Buri in 2016. A voucher specimen is deposited at the Faculty of Science, Ramkhamhaeng University, Thailand (Apichart Suksamrarn, No. 091).

\section{Extraction and isolation}

The fresh tubers of $S$. venosa $(0.5 \mathrm{~kg})$ were sliced, air-dried, milled, and macerated successively with $n$-hexane, EtOAc, and $\mathrm{MeOH}$ at room temperature. The filtered solution of each extraction was evaporated under reduced pressure at temperature $40-45^{\circ} \mathrm{C}$ to give the hexane $(875 \mathrm{mg})$, EtOAc $(2.5 \mathrm{~g})$, and $\mathrm{MeOH}$ (2.2 g), respectively. The EtOAc extract ( $2.5 \mathrm{~g})$ was purified by silica gel column chromatography $\left(\mathrm{CH}_{2} \mathrm{Cl}_{2}-\mathrm{MeOH}, 99: 1-98: 2\right)$ to afford dehydrostephanine (1.6 mg, Figure 1B) and (-)-stephanine $(62.0$ 
http://wjst.wu.ac.th

mg, Figure 1A). The isolated compounds were characterized by spectroscopic methods and comparison of physical properties with those reported in the literature $[8,12]$.

A<smiles>COc1cccc2c1CC1CC3=CC4=C(OCO4)C3=C1CCN2C</smiles>

(-)-Stephanine
B<smiles>COc1cccc2c1cc1c3c(cc4c(c32)OCO4)CCN1C</smiles>

Dehydrostephanine

Figure 1 Structures of (A) (-)-stephanine and (B) dehydrostephanine.

\section{Cell culture}

RAW264.7 cells (ATCC, Manassas, VA) were grown in RPMI-1640 (Corning, New York, USA) supplemented with $10 \%$ endotoxin-free fetal bovine serum (Biochrom GmbH, Berlin, Germany), $1 \%$ penicillin/streptomycin (Gibco, Gaithersburg, USA), and $2 \mathrm{mM}$ stable glutamine (Gibco, Gaithersburg, USA). The cells were maintained in a humidified atmosphere of $5 \% \mathrm{CO}_{2}$ at $37^{\circ} \mathrm{C}$.

\section{Cell viability}

RAW264.7 cells were seeded into 96-well plates at a density of $1.0 \times 10^{5}$ cells/well for $24 \mathrm{~h}$. Cells were pre-treated with different concentrations $(5-160 \mu \mathrm{M})$ of $(-)$-stephanine, dehydrostephanine, and a standard drug dexamethasone for $1 \mathrm{~h}$ followed by LPS $(10 \mathrm{ng} / \mathrm{mL})$ treatment for $24 \mathrm{~h}$. After that, cells were incubated with MTT solution $(0.5 \mathrm{mg} / \mathrm{mL})$ for another $3 \mathrm{~h}$, and the solution was discarded. After incubation, the formazan crystal in each well was dissolved by $200 \mu \mathrm{L}$ of DMSO. The absorbance of the formazan solution was detected at a wavelength of $560 \mathrm{~nm}$ and $670 \mathrm{~nm}$ using a microplate reader (Thermo Fisher, USA). \% Cell viability was calculated compared with control using the following equation:

$\%$ Cell viability $=[($ Abs treated sample $/$ Abs untreated sample $) \times 100]$

The half-maximal cytotoxic concentration $\left(\mathrm{CC}_{50}\right)$ of $(-)$-stephanine, dehydrostephanine, and dexamethasone at concentrations of $5-160 \mu \mathrm{M}$ were determined from a dose-response curve by using non-linear regression of GraphPad Prism 6. Data were obtained from three independent experiments in triplicates.

\section{Measurement of nitrite by Griess assay}

Nitrite, a stable end product of NO formation, was determined by Griess reagent. RAW264.7 cells were seeded into 96-well plates and pre-treated with nontoxic doses of (-)-stephanine $(5-40 \mu \mathrm{M})$, dehydrostephanine $(5-80 \mu \mathrm{M})$, and a standard drug dexamethasone $(5-160 \mu \mathrm{M})$ for $1 \mathrm{~h}$ before LPS $(10 \mathrm{ng} / \mathrm{mL})$ stimulation. After $24 \mathrm{~h}$ incubation, $75 \mu \mathrm{L}$ of culture media were collected and mixed with 65 $\mu \mathrm{l}$ of distilled water and $10 \mu \mathrm{L}$ of Griess reagent $(0.1 \%$ naphthylethylene, $2 \%$ sulfanilamide, and $2.5 \%$ phosphoric acid solution) in 96-well plates to determine the levels of nitrite in culture medium. After incubation at room temperature for $30 \mathrm{~min}$, the absorbance was measured using a microplate reader at $540 \mathrm{~nm}$.

The half-maximal NO inhibitory concentration $\left(\mathrm{IC}_{50}\right)$ of dehydrostephanine at doses of $5-80 \mu \mathrm{M}$ and dexamethasone at doses of $5-160 \mu \mathrm{M}$ were determined from a dose-response curve following 10 
http://wjst.wu.ac.th

ng/ml LPS treatment for $24 \mathrm{~h}$ by using non-linear regression of GraphPad Prism 6. $\mathrm{IC}_{50}$ of (-)-stephanine at doses of $5-40 \mu \mathrm{M}$ could not be calculated by using GraphPad Prism 6 software. Data were obtained from three independent experiments in triplicates.

\section{Measurement of pro-inflammatory cytokines by ELISA}

Cells were seeded at a density of $1.0 \times 10^{5}$ cells/well into 96 -well plates for $24 \mathrm{~h}$. After that, cells were pre-treated with $20-80 \mu \mathrm{M}$ dehydrostephanine and $10 \mu \mathrm{M}$ dexamethasone for $1 \mathrm{~h}$ followed by stimulation with $10 \mathrm{ng} / \mathrm{mL}$ LPS for $24 \mathrm{~h}$. The culture supernatants were collected and the levels of pro-inflammatory cytokines including TNF- $\alpha$, IL-1 $\beta$, and IL-6 were determined using commercial ELISA kits according to the manufacturer's instructions.

\section{Selectivity index (SI)}

SI values were performed in order to determine the selectivity of the compounds on the inhibition of NO secretion over cytotoxicity. High SI value indicates the high inhibition of NO secretion with low cytotoxicity. SI value of each compound is a ratio of $\mathrm{CC}_{50}$ and $\mathrm{IC}_{50}$ as shown below.

SI value $=\left(\mathrm{CC}_{50}\right.$ value of MTT assay $/ \mathrm{IC}_{50}$ value of Griess assay $)$

\section{Statistical analysis}

Data were obtained from three independent experiments. The results were expressed as the mean \pm SEM. All statistical differences among the different groups were observed via one-way ANOVA followed by Dunnett's test using GraphPad Prism 6 (GraphPad Software, Inc., La Jolla, CA, USA). Significant difference was considered at $\mathrm{p}<0.05$.

\section{Results and discussion}

Effects of (-)-stephanine and dehydrostephanine from $S$. venosa on cell viability

Steroids and non-steroidal anti-inflammatory drugs (NSAIDs) are widely used to relieve inflammatory diseases. However, these drugs possess several limitations and side effects [16]. The way to find the minimal side effects of the anti-inflammatory drug, better potential has inspired this research. Herbal remedies are currently used for the treatment of diseases more than four thousand years and some herbs are still widely used for the treatment of inflammatory-related diseases in traditional medicine [17]. In the present study, the cytotoxic effects of aporphine alkaloids, (-)-stephanine and dehydrostephanine isolated from the tuber of $S$. venosa have been investigated in LPS-activated RAW264.7 macrophages. The effects of the two isolated compounds (-)-stephanine (Figure 2A) and dehydrostephanine (Figure 2B) on the cytotoxicity of RAW264.7 cells were evaluated using MTT assay. Dehydrostephanine at concentrations up to $80 \mu \mathrm{M}$ had no significant cytotoxic effect on RAW264.7 macrophages (Figure 2B). However, (-)-stephanine at concentrations of 80 - $160 \mu \mathrm{M}$ exhibited significant cytotoxicity (Figure 2A). $\mathrm{CC}_{50}$ values of the compounds (-)-stephanine and dehydrostephanine were $52.37 \pm 0.13$ and $93.15 \pm 0.17$ $\mu \mathrm{M}$, respectively (Table 1), indicating less cytotoxic effect of dehydrostephanine than that of (-)-stephanine on RAW264.7 macrophages. Similar to our observation, aporphine alkaloid crebanine of less than $40 \mu \mathrm{M}$ did not affect cell viability of RAW264.7 macrophages [18]. For a standard drug, dexamethasone did not show any cytotoxicity at doses up to $160 \mu \mathrm{M}$ (Figure 2C).

\section{Effects of (-)-stephanine and dehydrostephanine from $S$. venosa on LPS-activated NO production in RAW264.7 cells \\ During the inflammatory response by pathogens, macrophages secrete large amounts of} inflammatory mediators via activating numerous signaling cascades [19,20]. NO is considered as a pro-inflammatory mediator that induces inflammation due to overproduction in high amounts from macrophages in abnormal situations [21]. Large amounts of NO induce both cytostasis and cytotoxicity to viruses, bacteria, fungi, protozoa, helminths, and tumor cells [22]. To assess the effect of the (-)-stephanine and dehydrostephanine on the inhibition of NO production in LPS-activated RAW264.7 
http://wjst.wu.ac.th

macrophages, cells were pre-treated with (-)-stephanine $(5-40 \mu \mathrm{M})$ and dehydrostephanine $(5-80 \mu \mathrm{M})$ for $1 \mathrm{~h}$ following the $10 \mathrm{ng} / \mathrm{ml}$ LPS stimulation for $24 \mathrm{~h}$. After incubation, the levels of NO secretion were detected using Griess reagent. Pre-treatment with (-)-stephanine $\left(\begin{array}{lll}40 & \mu \mathrm{M}\end{array}\right)$ (Figure $\left.\mathbf{3 A}\right)$ and dehydrostephanine $(40-80 \mu \mathrm{M})$ (Figure 3B) significantly inhibited the production of NO compared with the LPS-stimulated cells.
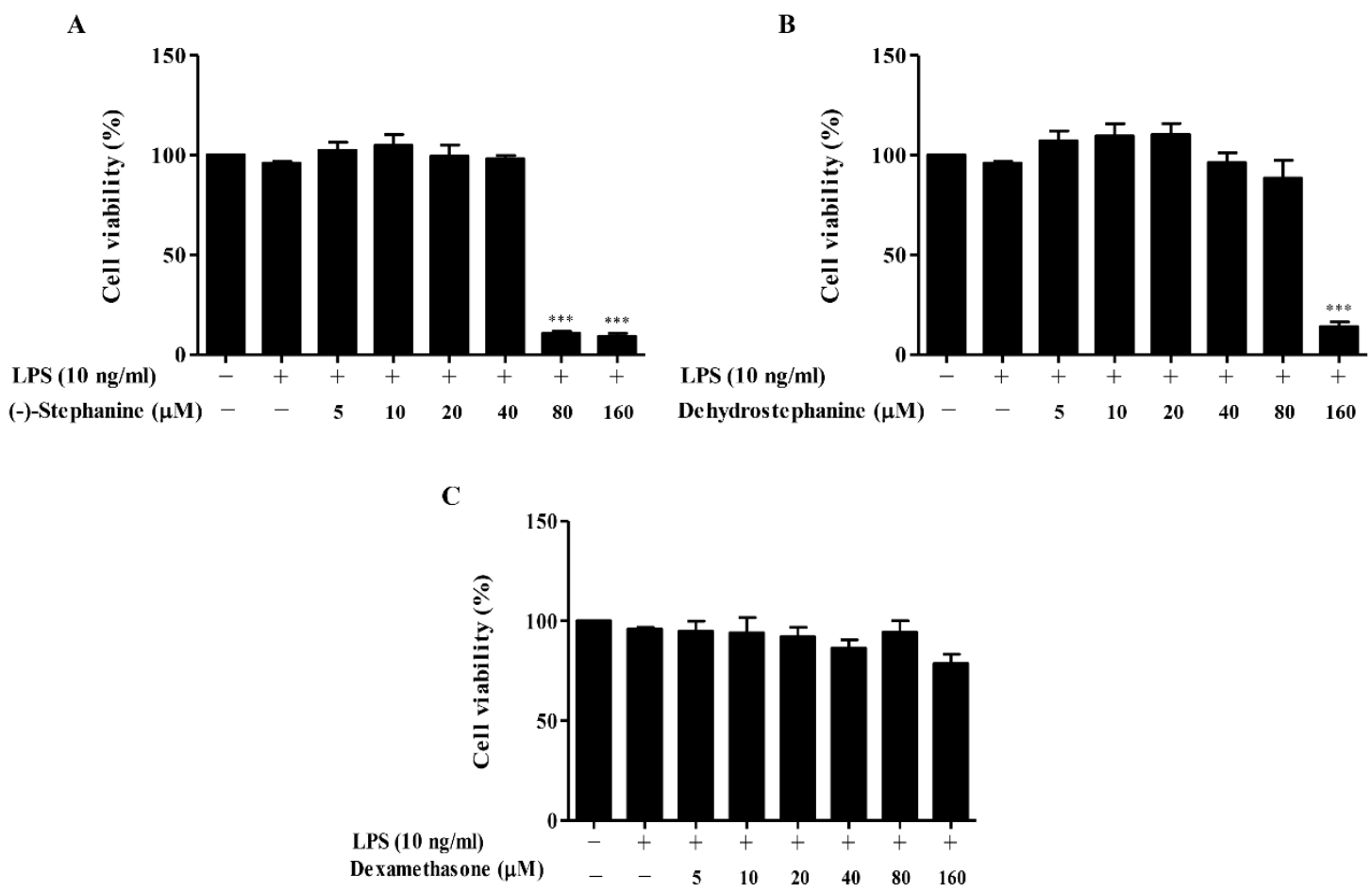

Figure 2 Effects of (-)-stephanine, dehydrostephanine, and dexamethasone on cell viability in RAW264.7 cells. Cells were treated with various concentrations $(5-160 \mu \mathrm{M})$ of (A) (-)-stephanine, (B) dehydrostephanine, and (C) dexamethasone in the presence of $10 \mathrm{ng} / \mathrm{ml}$ LPS treatment for $24 \mathrm{~h}$ followed by MTT assay. The symbols " - " and " + " are denoted as the absence and presence of the compounds, respectively. Values are expressed as mean \pm SEM of three independent experiments in triplicate. $* * *, p<0.001$ versus control without any treatment.

$\mathrm{IC}_{50}$ values of (-)-stephanine and dehydrostephanine were $>40 \mu \mathrm{M}$ and $26.81 \pm 0.25 \mu \mathrm{M}$, respectively (Table 1). However, NO inhibitory activity of the two compounds are less potent than that of the antiinflammatory drug dexamethasone $\left(\mathrm{IC}_{50}=7.88 \pm 0.21 \mu \mathrm{M}\right)$ (Figure 3C and Table 1). Similar to our results, crebanine, $O$-methylbulbocapnine, and dicentrine could inhibit NO production by suppression of iNOS protein expression in LPS-activated RAW264.7 cells [9,18]. To assess the selectivity of NO inhibition over cytotoxicity, SI values were calculated. Dehydrostephanine had SI value of 3.47 (Table 1). Dehydrostephanine represents the high inhibition of NO production with low cytotoxicity. 
http://wjst.wu.ac.th

\section{Effect of dehydrostephanine on the secretion of pro-inflammatory cytokines}

Macrophages are the main sources of pro-inflammatory cytokines IL-1 $\beta$, IL-6, and TNF- $\alpha$ [4]. These three major cytokines are potent pyrogenic cytokines that induce fever and regulate the inflammatory response [4]. IL-1 $\beta$ is an important inflammatory mediator in response to infections, inflammation, and stress [23]. TNF- $\alpha$ is one of the first cytokine to be released in response to microbial products and inflammation. This cytokine is involved in systemic inflammatory response [24]. Similar to the first two cytokines, IL- 6 promotes fever and regulates the inflammatory process $[25,26]$. These three cytokines are directly involved in inflammatory reactions and have been implicated in the pathogenesis of many inflammatory diseases [27].

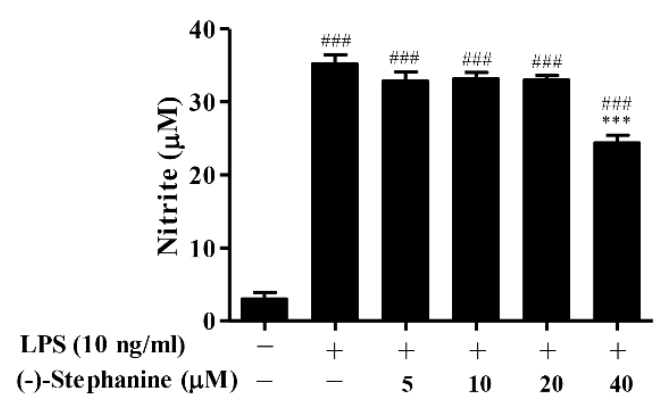

LPS (10 ng/ml) Dehydrostephanine $(\mu M)-$

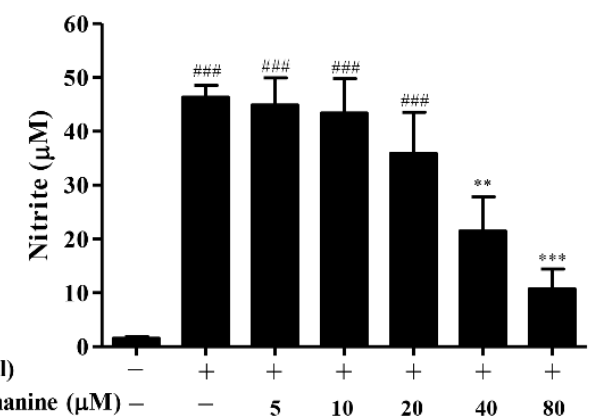

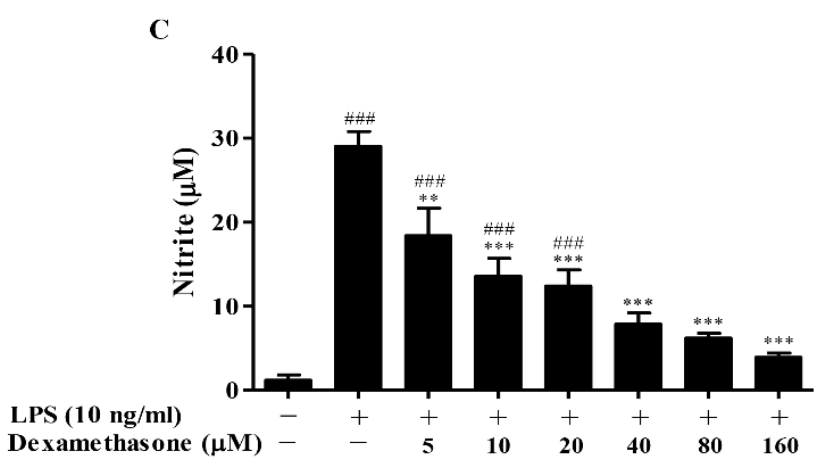

Figure 3 Effects of (-)-stephanine, dehydrostephanine, and dexamethasone on NO production in LPS-activated RAW264.7 cells. Cells were pre-treated with different concentrations of (A) (-)-stephanine, (B) dehydrostephanine, and (C) dexamethasone for $1 \mathrm{~h}$ followed by $10 \mathrm{ng} / \mathrm{mL}$ of LPS treatment for $24 \mathrm{~h}$. The culture supernatant was then subjected to Griess assay. The symbols " - " and " $+"$ are denoted as the absence and presence of the compounds, respectively. Values are expressed as mean \pm SEM of three independent experiments in triplicate. \#\#\#, p $<0.001$ versus control without any treatment; $* *, \mathrm{p}<0.01, * * *, \mathrm{p}<0.001$ versus LPS-stimulated cells. 
http://wjst.wu.ac.th

Table $1 \mathrm{CC}_{50}, \mathrm{IC}_{50}$, and SI values of (-)-stephanine and dehydrostephanine from $S$. venosa and dexamethasone.

\begin{tabular}{cccc}
\hline Compound & $\mathbf{C C}_{50}(\mu \mathbf{M})$ & $\mathbf{I C}_{50}(\mu \mathbf{M})$ & SI value \\
\hline$(-)$-Stephanine & $52.37 \pm 0.13$ & $>40$ & N/A \\
Dehydrostephanine & $93.15 \pm 0.17$ & $26.81 \pm 0.25$ & 3.47 \\
Dexamethasone & $>160$ & $7.88 \pm 0.21$ & N/A \\
\hline
\end{tabular}

N/A, not applicable

$\mathrm{CC}_{50}$, the half-maximal cytotoxic concentration

$\mathrm{IC}_{50}$, the half-maximal NO inhibitory concentration

SI, selectivity index

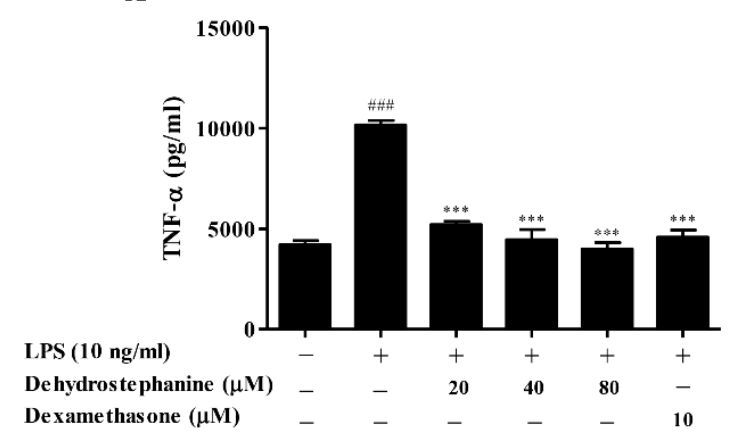

B

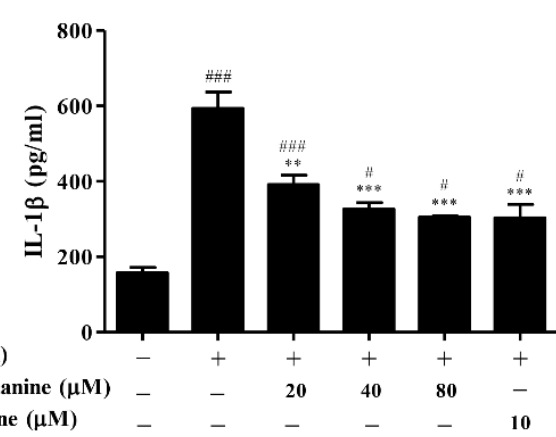

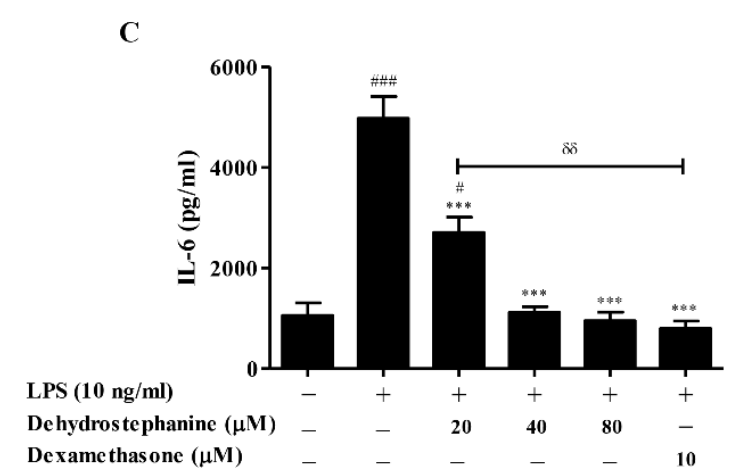

Figure 4 Effect of dehydrostephanine on the pro-inflammatory cytokine secretion in LPS-induced RAW264.7 cells. Cells were pre-treated with $20-80 \mu \mathrm{M}$ dehydrostephanine for $1 \mathrm{~h}$ followed by 10 $\mathrm{ng} / \mathrm{mL}$ LPS treatment for $24 \mathrm{~h}$. The levels of pro-inflammatory cytokines (A) TNF- $\alpha$, (B) IL-1 $\beta$, and (C) IL-6 in LPS-activated RAW264.7 cells were determined using ELISA. The symbols " - " and " + " are denoted as the absence and presence of the compounds, respectively. Values are expressed as mean \pm SEM of three independent experiments. \#, $\mathrm{p}<0.05$, \#\#, $\mathrm{p}<0.001$ versus control without any treatment; **, $\mathrm{p}$ $<0.01, * * *, p<0.001$ versus LPS-stimulated cells; $\delta \delta, p<0.01$ versus dexamethasone. 
http://wjst.wu.ac.th

We further investigated whether dehydrostephanine modulated the production of these three major pro-inflammatory cytokines in LPS-stimulated RAW264.7 cells. As shown in Figure 4, all of the pro-inflammatory cytokines were markedly elevated upon LPS activation. Treatment of the cells with dehydrostephanine at concentrations of $20-80 \mu \mathrm{M}$ significantly decreased LPS-induced TNF- $\alpha$, IL-1 $\beta$, and IL-6 production in a dose-dependent manner (Figure 4A - 4C). The suppression of TNF- $\alpha$ and IL-1 $\beta$ by dehydrostephanine at concentrations of $20-80 \mu \mathrm{M}$ were comparable to that of $10 \mu \mathrm{M}$ dexamethasone. For IL-6, dehydrostephanine at concentrations of $40-80 \mu \mathrm{M}$ significantly inhibited the secretion to the same degree as that observed by $10 \mu \mathrm{M}$ dexamethasone. Thus, dehydrostephanine possesses antiinflammatory effect via suppression of pro-inflammatory cytokines.

TNF- $\alpha$ production from activated macrophages has been shown to promote the release of many other inflammatory mediators including IL-6, IL-12/23(p40), and the type I interferons [28]. For IL-1 $\beta$, this cytokine is secreted from macrophages via the process called inflammasome upon immune cell sensing of infection or cell stress [29]. The prolonged secretion of these inflammatory mediators in macrophages causes several inflammatory-related diseases [5,30]. As dehydrostephanine markedly suppressed NO and the three pro-inflammatory cytokines, dehydrostephanine may exhibit broad-spectrum anti-inflammatory activity potentially through its effect on transcriptional regulation of pro-inflammatory genes.

Many studies have reported that aporphine alkaloids from $S$. venosa and other plants possess anti-inflammation. $O$-Methylbulbocapnine and dicentrine isolated from $S$. venosa possessed the inhibitory effect on LPS-induced TNF- $\alpha$ and IL- 6 release by blocking AP-1 and NF- $\kappa$ B activation through inhibiting MAPKs and Akt signaling [9]. Nuciferine, aporphine alkaloid from the leaves of Nelumbo nucifera, inhibited TLR4/MyD88/NF- $\mathrm{KB}$ signaling and that leading to the reduction of serum and renal IL-1 $\beta$ levels in chemical-induced hyperuricemic mice as well as in uric acid-induced human proximal renal tubular epithelial (HK-2) cell in vitro [31]. Preliminary structure-activity relationship (SAR) investigation indicated that the presence of a double bond at the 6a,7-position of dehydrostephanine resulted in an increase of anti-inflammatory activity. Increased skeletal rigidity and conjugation of dehydrostephanine may facilitate the infusion of the dehydrogenated compound to the cells and thus leading to its biological effect [32]. Taken together, aporphine alkaloid dehydrostephanine exhibited anti-inflammatory effect by suppression of inflammatory mediators NO and pro-inflammatory cytokines and this may be involved at least in part in the suppression of several signaling pathway activation.

\section{Conclusions}

The present study showed for the first time that aporphine alkaloid dehydrostephanine isolated from $S$. venosa possessed an anti-inflammatory effect by suppressing inflammatory mediators NO and pro-inflammatory cytokines including TNF- $\alpha$, IL-1 $\beta$, and IL-6 secretion in LPS-activated RAW264.7 macrophages with less cytotoxic effect on the cells. Dehydrostephanine isolated from $S$. venosa may be a promising candidate compound for treating chronic inflammatory diseases.

\section{Acknowledgments}

This research was granted by Walailak University Fund for graduate studentships to W. Chulrik [WU60608 and No.06/2562] and C. Jansakun [No.020101/02/2559 and 09/2561], The National Research Council of Thailand [No.113/2561], The Royal Golden Jubilee Ph.D. Program, and The Thailand Research Fund (DBG6180030). 


\section{References}

[1] E Stylianou. Epigenetics of chronic inflammatory diseases. J. Inflamm. Res. 2019; 12, 1-14.

[2] JL Schultze and P Rosenstiel. Systems medicine in chronic inflammatory diseases. Immunity 2018; 48, 608-13.

[3] S Akira, S Uematsu and O Takeuchi. Pathogen recognition and innate immunity. Cell 2006; 124, 783-801.

[4] GA Duque and A Descoteaux. Macrophage cytokines: Involvement in immunity and infectious diseases. Front. Immunol. 2014; 5, 491-502.

[5] Z Wu, M Han, T Chen, W Yan and Q Ning. Acute liver failure: Mechanisms of immune-mediated liver injury. Liver Int. 2010; 30, 782-94.

[6] G Marelli, A Sica, L Vannucci and P Allavena. Inflammation as target in cancer therapy. Curr. Opin. Pharmacol. 2017; 35, 57-65.

[7] K Ingkaninan, P Phengpa, S Yuenyongsawad and N Khorana. Acetylcholinesterase inhibitors from Stephania venosa tuber. J. Pharm. Pharmacol. 2006; 58, 695-700.

[8] JT Blanchfield, DPA Sands, CHL Kennard and KA Byriel. Characterisation of alkaloids from some Australian Stephania (Menispermaceae) species. Phytochemistry 2003; 63, 711-20.

[9] S Yodkeeree, C Ooppachai, W Pompimon and P Limtrakul. O-Methylbulbocapnine and dicentrine suppress LPS-induced inflammatory response by blocking NF- $\kappa \mathrm{B}$ and AP-1 activation through inhibiting MAPKs and Akt signaling in RAW264.7 macrophages. Biol. Pharm. Bull. 2018; 41, 1219-27.

[10] PM Le, V Srivastava, TT Nguyen, B Pradines, M Madamet, L Mosnier, TT Trinh and H Lee. Stephanine from Stephania venosa (Blume) Spreng showed effective antiplasmodial and anticancer activities, the latter by inducing apoptosis through the reverse of mitotic exit. Phytother. Res. 2017; 31, 1357-68.

[11] DK Semwal, R Badoni, R Semwal, SK Kothiyal, GJP Singh and U Rawat. The genus Stephania (Menispermaceae): Chemical and pharmacological perspectives. J. Ethnopharmacol. 2010; 132, 369-83.

[12] J Kunitomo, M Oshikata and M Akasu. The alkaloids of Stephania cepharantha Hayata cultivated in Japan (ii) (author's transl). Yakugaku Zasshi. 1981; 101, 951-5.

[13] S Nantapap, C Loetchutinat, P Meepowpan, N Nuntasaen and W Pompimon. Antiproliferative effects of alkaloids isolated from the tuber of Stephania venosa via the induction of cell cycle arrest in mammalian cancer cell lines. Am. J. Applied Sci. 2010; 7, 1057-65.

[14] S Yodkeeree, P Wongsirisin, W Pompimon and P Limtrakul. Anti-invasion effect of crebanine and $O$-methylbulbocapnine from Stephania venosa via down-regulated matrix metalloproteinases and urokinase plasminogen activator. Chem. Pharm. Bull. 2013; 61, 1156-65.

[15] K Bunluepuech and S Tewtrakul. Anti-HIV-1 integrase activity of Thai medicinal plants in longevity preparations. Songklanakarin J. Sci. Tech. 2011; 33, 693-7.

[16] M Manrique-Moreno, L Heinbockel, M Suwalsky, P Garidel and K Brandenburg. Biophysical study of the non-steroidal anti-inflammatory drugs (NSAID) ibuprofen, naproxen and diclofenac with phosphatidylserine bilayer membranes. Biochim. Biophys. Acta 2016; 1858, 2123-31.

[17] A Serrano, G Ros and G Nieto. Bioactive compounds and extracts from traditional herbs and their potential anti-inflammatory health effects. Medicines 2018; 5, 76-84.

[18] P Intayoung, P Limtrakul and S Yodkeeree. Antiinflammatory activities of crebanine by inhibition of NF- $\kappa$ B and AP-1 activation through suppressing MAPKs and Akt signaling in LPS-induced RAW 264.7 macrophages. Biol. Pharm. Bull. 2016; 39, 54-61.

[19] D Hirayama, T Iida and H Nakase. The phagocytic function of macrophage-enforcing innate immunity and tissue homeostasis. Int. J. Mol. Sci. 2017; 19, 92-105.

[20] J Yin, KL Valin, ML Dixon and JW Leavenworth. The role of microglia and macrophages in CNS homeostasis, autoimmunity, and cancer. J. Immunol. Res. 2017; 2017, 5150678.

[21] JN Sharma, A Al-Omran and SS Parvathy. Role of nitric oxide in inflammatory diseases. Inflammopharmacology 2007; 15, 252-9. 
http://wjst.wu.ac.th

[22] J MacMicking, Q Xie and C Nathan. Nitric oxide and macrophage function. Annu. Rev. Immunol. 1997; 15, 323-50.

[23] TA Samad, KA Moore, A Sapirstein, S Billet, A Allchorne, S Poole, JV Bonventre and CJ Woolf. Interleukin-1beta-mediated induction of Cox-2 in the CNS contributes to inflammatory pain hypersensitivity. Nature 2001; 410, 471-5.

[24] BA Beutler. The role of tumor necrosis factor in health and disease. J. Rheumatol. Suppl. 1999; 57, 16-21.

[25] F Schaper and S Rose-John. Interleukin-6: Biology, signaling and strategies of blockade. Cytokine Growth F. R. 2015; 26, 475-87.

[26] C Gabay. Interleukin-6 and chronic inflammation. Arthritis Res. Ther. 2006; 8, S3.

[27] DL Scott, F Wolfe and TW Huizinga. Rheumatoid arthritis. Lancet 2010; 376, 1094-108.

[28] K Hamidzadeh, SM Christensen, E Dalby, P Chandrasekaran and DM Mosser. Macrophages and the recovery from acute and chronic inflammation. Annu. Rev. Physiol. 2017; 79, 567-92.

[29] M Monteleone, JL Stow and K Schroder. Mechanisms of unconventional and secretion of IL-1 family cytokines. Cytokine 2015; 74, 213-8.

[30] RA Balk. Pathogenesis and management of multiple organ dysfunction or failure in severe sepsis and septic shock. Crit. Care Clin. 2000; 16, 337-52.

[31] MX Wang, YL Liu, Y Yang, DM Zhang and LD Kong. Nuciferine restores potassium oxonateinduced hyperuricemia and kidney inflammation in mice. Eur. J. Pharmacol. 2015; 747, 59-70.

[32] H Wang, X Cheng, S Kong, Z Yang, H Wang, Q Huang, J Li, C Chen and Y Ma. Synthesis and structure-activity relationships of a series of aporphine derivatives with antiarrhythmic activities and acute toxicity. Molecules 2016; 21, 1555. 